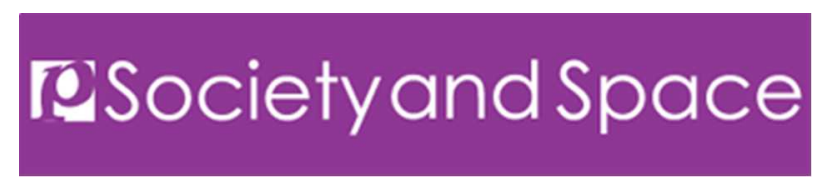

\title{
Sustainability and the financialisation of commercial property: making prime and non-prime markets
}

\begin{tabular}{|r|l|}
\hline Journal: & Environment and Planning D: Society and Space \\
\hline Manuscript ID & EPD-2014-0087.R3 \\
\hline Manuscript Type: & Article \\
\hline Keywords: & $\begin{array}{l}\text { commercial property market, sustainability, calculation, financialisation, } \\
\text { valuing }\end{array}$ \\
\hline
\end{tabular}

SCHOLARONE

Manuscripts 


\section{Sustainability and the financialisation of commercial property:} making prime and non-prime markets

\section{Introduction:}

This paper situates itself at the intersection of two important trends affecting the built environment: the sustainability agenda and the financialisation of the commercial property market. The commercial property sector is understood as comprising a range of nondomestic buildings and premises; retail, office and industrial (warehousing and factories) are the main uses, together with some smaller subsectors. The analysis questions the extent to which financialisation has penetrated the commercial property market, pointing to its concentration in the most valuable 'prime' sector, and suggests that equal attention should be paid to the more prevalent but less financially valuable non-prime sector. It argues that engagement with the sustainability agenda is quite different across the two sectors and using a new economic sociology framework relates this to the construction of the object of exchange in these sectors and the modalities of valuation that operate. This has implications for the uptake of the sustainability agenda across the built environment.

The argument unfolds from an account of the sustainability agenda as it relates to commercial property, identifying the very partial nature of current research on this. It then situates this within a discussion of financialisation and whether this applies across the commercial property market. This brings the terms 'prime' and 'non-prime' to the forefront of the analysis and sets up the key focus of the paper as the engagement of a partiallyfinancialised commercial property market with sustainability concerns. The conceptual 
framework that is used to progress the analysis is then introduced. Callon's economization project is outlined and links made to contemporary valuation studies. Key concepts are defined: the construction of the objects of exchange within markets; the modalities of valuation and specific calculative tools; and the performativity of these processes. This leads on to the analysis of prime and non-prime commercial property sectors, using these concepts, to understand how sustainability may impact commercial property as a whole, and hence commercial areas within the built environment.

\section{Commercial property and the sustainability agenda}

It is almost three decades since the Brundtland report popularised the concept of sustainability - with its holistic emphasis on environmental, social and economic interconnections - and the term has penetrated many areas; the property sector is no exception. Within the academic, policy and professional literature, there is now an established body of texts considering the application of the sustainability agenda to the property sector and, in particular, commercial property. While the professional and academic literature makes reference to the holistic nature of the sustainability concept, it is clear that the dominant construction of sustainable commercial property concentrates on environmental issues and within that, carbon and energy (Sayce et al., 2010). A review of websites on sustainability and commercial property (see below for the methodology) found that $65 \%$ of sites saw sustainability in terms of energy and $60 \%$ in terms of carbon.

The policy frameworks for promoting the sustainability of commercial property have similarly been heavily focussed on energy and carbon emissions. The most symbolic measure is that confirmed by the Government's Carbon Plan (HMG, 2011) that all new nondomestic property should be zero carbon by 2019 . Collectively commercial property 
(excluding factories and the production activities that occur within them) currently accounts for about $8.25 \%$ of UK energy consumption; this translates into about $15 \%$ of $\mathrm{CO} 2$ emissions (RICS, 2013). The split of these emissions between uses shows that industry is responsible for about $24 \%$ of emissions, with retail premises at just over $21 \%$ and offices accounting for $8 \%$ (see Figure 1).

[Insert Figure 1 about here]

For existing commercial properties, the largest energy users in the commercial sector are subject to the requirement to buy permits to cover their carbon emissions under the CRC Energy Efficiency Scheme but the measure that has the broadest coverage in the commercial property market arises from the energy certification of buildings. The 2002 European Directive on the Energy Performance of Buildings (2002/91/EC) required many commercial buildings to be assessed for an Energy Performance Certificate (EPC). An EPC rates the energy efficiency of a building and is valid for 10 years, with the highest rating (most efficient) being ' $A$ ' and the least ' $G$ '. An EPC is required for any premises being rented out or sold or for a completed newly constructed building. Changes to a building altering the number of parts for separate occupation may also require an EPC. Failure to make an EPC available to a prospective tenant or purchaser can incur a fine based on the building's rateable value. There are specific exemptions relating to: listed and protected buildings' temporary structures; places of worship; production sites with low energy consumption; small detached buildings; and buildings due to be demolished.

The Directive was revised in 2010 (2010/31/EU), with provisions for Minimum Energy Efficiency Standards (MEES) implemented in England and Wales through S.49 of the 2011 Energy Act and put into force by 2015 regulations, with effect from $1^{\text {st }}$ April 2018. Under 
these all commercial property offered for rent will have to demonstrate at least an 'E' EPC energy rating. This will apply to all new leases and lease renewals, where the term is greater than 6 months and less than 99 years, and the fine for non-compliance are substantial at $£ 5,000-150,000$. There are exemptions where: identified improvement measures can be shown to be non-viable within a seven-year payback period; the necessary consents from tenants, lenders and superior landlords cannot be obtained; or 'a relevant suitably qualified expert' states in writing that the improvement measures will reduce the property's value by $5 \%$ or more. The property sector has variously assessed that between $13-20 \%$ of commercial property has an EPC rating of ' $F$ ' or ' $G$ ' and that 2-5\% of investment income comes from properties with such ratings (Chadha, 2012, Zurich, 2013); furthermore, some $34 \%$ of commercial properties do not currently have an EPC at all (Chadha, 2012).

This focus on operational energy consumption and associated carbon emissions is slowly being matched by attention to the embodied carbon associated with the production and transportation of construction materials. The CEN/TC 350 process is being conducted at EU level to develop voluntary standards for the assessment of the sustainability of new and existing construction works and for the environmental product declaration of construction materials (Ascui and Lovell, 2011). This is leading to some activity in assessing embodied carbon for new developments and refurbishments.

There is also a range of classificatory frameworks seeking to assess new commercial developments and refurbishments from a broader sustainability perspective (Joss et al., 2015). These schemes are increasingly being incorporated into planning decision-making on development proposals. At a building-scale the most commonly adopted scheme within the UK is BREEAM; a neighbourhood scale version BREEAM Communities is now available for 
the masterplanning of major urban redevelopment schemes. BREEAM parallels schemes such as LEED, LEED-ND, GreenStar, CASBE, etc. that operate more commonly in other countries. Such schemes work by identifying an extensive menu of features of a development as 'sustainable' and rewarding them with 'credits'; some credits may be mandatory. Usually credits are weighted and aggregated to provide an overall score and/or classification. There are BREEAM classification schemes for different types of development, including various commercial categories (Cole, 2006; Schweber, 2013).

There is, therefore, an established sustainability agenda in place relevant to the commercial property market, albeit one very focussed on energy use and carbon emissions. The academic literature in response has taken a very particular perspective. Some work, often more technical in nature, has concentrated on identifying how buildings may be made more sustainable through changing the building fabric, its facilities and associated operational routines (e.g. Fieldson and Rai, 2009; Newell, 2009). The main emphasis, though, has been on considering whether sustainability features add value within the property market. The argument here is that if such features can be shown to add value, there will be an incentive for market actors to promote sustainability. Work within this line includes: Lützkendorf and Lorenz, 2005; Ellison and Sayce, 2006; Sayce et al., 2007; Levy and De Francesco, 2008; Fuerst and McAllister, 2009; Dixon, 2009; Sayce et al., 2009; Sayce et al., 2010; WarrenMyers, 2012; Fuerst et al., 2013. It parallels the professional interest in how to value sustainability properties set out in the RICS Valuation Information Paper No. 13 (2009).

This literature is partial in a number of respects. First, it is normatively concerned to consider sustainability in terms of its market value; the perspective adopted is of the assumed market actor, the consumer and purchaser of commercial property. Second, the 
conceptual framework is that provided by neo-classical economics, with its supply and demand dynamics and benchmark of perfect competition. Third, this academic neo-classical construction of a market is taken as an unquestioned reality, as already existing 'out there' (Callon, 1998a; MacKenzie, Muniesa and Siu, 2007). A different approach is taken here, looking at markets as socially constructed entities and raising the question of how this enables one to consider the impact of the sustainability agenda on commercial property. Before setting out this conceptual framework in more detail, an important trend affecting the commercial property market - financialisation - is addressed.

\section{Financialisation and the commercial property market}

There is a growing body of literature that points to financialisation as a major contemporary socio-economic trend (Christopherson et al., 2013; Layfield, 2013; Müller, 2014; Zhang and Andrew, 2014; Forrest and Hirayama, 2015). Such financialisation can be seen as a particular form of economicization, that is the process "through which activities and behaviours and spheres or fields are established as being economic" (Caltskan and Callon, 2009: 370). Chiapello (2015: 15) sees it as a transformation in the nature of capitalism, one that involves "the capture of resources by finance in the broadest sense through expansion of the financial markets, a rise in the number and variety of financial operators and finally the development of a service industry associated with financial activities".

She goes on to emphasise the importance of new modes of valuation within financialisation, valuation involving "specific 'financialised" techniques and calculation methods" (ibid). Financialised valuation is defined as: "valuation processes equipped by models, instruments, and representations belonging to the explicit knowledge underpinning the approach and practices of finance professionals" (op.cit.: 5). Three particular aspects are identified: the 
reliance on market prices as indicator of worth; probability-based estimation of risk; and the use of discounted cashflow (DCF) techniques to calculate Net Present Value (NPV). These are seen as increasingly displacing valuations based on costs, non-probability-based assessments of risk and non-investment interests.

As an important sector of the UK economy, commercial property might be expected to be subject to these financialisation trends. In terms of its value, the commercial property sector was estimated to be worth $f 569$ bn in 2012 , which is nearly as large as the country's stock of plant, machinery and vehicles, a third the value of government bonds or about $30 \%$ that of UK equities. Commercial property comprises largely retail, office and industrial uses (89\% of this total by value). Retail property is worth $£ 207$ bn followed by offices at $£ 157$ bn, warehousing at $£ 80 \mathrm{bn}$, factories at $£ 60$ bn and other commercial property at $£ 65$ bn. On average over $£ 50$ m.sq.ft. is added to the UK commercial property sector each year with an investment value of about $1 \%$ of GDP. (All data from RICS, 2013; see Figure 1.)

Such commercial property (alongside other property such as agricultural land and residential estates) has long been held as an investment. The RICS estimate that about twothirds of commercial property is rented and thus owned by a landlord as an investment asset, and that this figure has grown over the last decade (2013). This means that about $60 \%$ of the UK's office and retail stock and $25 \%$ of the industrial stock is owned as an investment (McNamara, 2015). By value, figures provided by Benford and Burrows (2013) suggest that $£ 464$ bn of UK commercial property or over $80 \%$ is occupied by renters. This emphasis on commercial property as an investment is reflected in the dominant form of valuation method for such assets known, not surprisingly, as the investment method. This is based upon the capitalising future rental income flows to a present value using an 'all risks yield' 
(representing the opportunity cost of investment and the specific risks of the particular property being valued) as the discount rate. Traditionally this was calculated using discount factors found in valuation tables, published since the early 20th century.

Financialisation has penetrated the commercial property market but only in one sector, the so-called 'prime' sector. 'Prime' is a term widely used within the property market to refer to buildings and developments which are attractive to institutional investors such as pensions funds, insurance companies and other major corporate property holders. Such properties are built and fitted out to a high specification incorporating the 'latest and newest' features and are typically described as 'Grade A' or of the highest 'quality'. They will be in locations that can be termed 'head quarter locations'. If a new development, they will be pre-let and tenants will be major companies who have a 'good covenant', which means that they are unlikely to vacate the premises unexpectedly or otherwise fail to pay rent.

McNamara (2015) states that a third of the commercial property sector is owned directly by UK insurance companies and pension funds (see also Hennebury and Robert, 2008), with overseas investors, listed property companies and private property companies each owning a further seventh; the remainder is owned by small businesses, charities and wealthy individuals (Benford and Burrows, 2013). The financial institutions (the pension funds and insurance companies) are major players. The value of their property investments is heavily concentrated in high-value locations: $21 \%$ of all commercial investment by value comprises Central London shops and offices; $17 \%$ is in purpose-built shopping centres. Shops and offices outside of Central London and such shopping centres amount to only $18 \%$ of the total investment value (data from IPD, which concentrates on financial institutions' holdings; summarised in RICS, 2013). While the proportion of their total investment 
portfolio directly held as property has fallen over the last two decades (McNamara, 2015), financial institutions continue to see an advantage to holding commercial property because of its perceived long-term security and the way that returns from property are countercyclical to those from other assets, notably equities. However, the scale of their involvement is now rivalled by overseas investors, particularly in locations such as the City of London.

This institutionally-dominated prime sector is where financialisation is having an impact in two inter-related ways. First, the method of valuation adopted is moving away from the traditional investment method towards the more sophisticated use of DCF techniques as valuation tables have been have been overtaken by software. This calculates property values as NPVs and further allows for Internal Rates of Return (the discount rate at which NPV equates to zero) to be calculated as an indicator of the rate of return on property investment. This contrasts with the use of comparables data from existing property market transactions on prices and rents to determine property investment yields (by dividing freehold capital values by rental income) as in the past. These shifts now put property investment on a par with other investment assets when calculating value and return. Second, the identification of property investment with the ownership of a discrete physical commercial unit - an office building, a shopping mall - is being broken by the development of 'paper' assets based on commercial property ownership. Thus direct ownership of individual properties by financial institutions is increasingly being replaced by investment in collective vehicles that own a portfolio of properties or unitised individual properties. In 2012 collective investment schemes accounted for $34 \%$ of the ownership of investment property (RICS, 2013). 
This emphasis on how financialisation has affected the prime commercial property market, important as it is, should not lead us to forget the rest of the market. Data on the value of commercial property overemphasises the importance of high value locations and the more expensive property held by institutional investors. There are numerous commercial premises that contribute relatively little to the overall value of the investment market. It is difficult to establish definitive data for the commercial property sector as a whole but the Valuation Office Agency record that in 2004 there were 1.4 million non-domestic properties in England and Wales (defined in terms of hereditaments, the business rate taxable unit). By area (sq.m.) this was distributed as follows: $17 \%$ offices; $19 \%$ retail units; $25 \%$ warehousing; and $38 \%$ factories (see Figure 1).

A ready indicator of the extent to which this comprises non-prime property is given by its age (since prime property by definition is relatively modern). Half of all commercial properties were built before 1940 and only $9 \%$ after 1990; by area just over a quarter of commercial building space was built before 1940 and only $15 \%$ since $1990.85 \%$ is therefore almost 20 years old and, by definition, non-prime. Retail space is disproportionately older; about $40 \%$ of this floorspace was built before 1940 compared to about $30 \%$ of office floorspace and $25 \%$ of industrial floorspace (GOS, 2008: 59).

Non-prime property is not only older but is typically owned by wealthy individuals and small local businesses, who "accounted for a significant amount of the investment in the small, local units that constitute much of the stock of 'secondary' quality commercial property" (Benford and Burrows, 2013: 53). It is also associated with substantial levels of bank lending. Sources give quite different figures for such bank debt but the pattern is consistent. Thomas (2011) states that, at minimum, $f 250$ bn (75\%) of real estate debt is secured against non- 
prime property and more than $f 100 \mathrm{~m}$ of commercial mortgage debt is backed by lower quality property; GVA (2011) claims that about $62 \%$ is secured against secondary property. Benford and Burrows (2013) note that using property as collateral against debt is more common among smaller companies, with $44 \%$ of SME bank loans by value secured on property.

However, the term non-prime is not a clear-cut as prime. It is defined by the absence of institutional investor interest and this can change over time. Prime institutional property investments may (indeed will) become non-prime due to physical ageing, changed occupier requirements and/or spatial shifts in property markets. The 'best' is a moving category and can only describe a limited portion of the market. The remainder comprises a mass of buildings and land which can be further sub-divided into secondary and tertiary, with tertiary representing the unit furthest in physical and market characteristics from prime.

So the commercial property market can be described as partially financialised, with financialised modes of valuation and asset creation penetrating the prime sector. Outside of this, the commercial property market comprises a wide range of buildings and premises that can be characterised as secondary or tertiary. While there has been a tendency in much real estate and planning literature to focus on prime property, it is important to consider the full range of commercial property. Urban areas are made up of prime and non-prime; indeed the physical majority of commercial property in our towns and cities will be non-prime. Furthermore all elements of the commercial property market are important from the point of view of the sustainability of the built environment. The key question that this paper addresses is how the prime and non-prime distinction interacts with the agenda for sustainability. 
Economizing through constructing, valuing, calculating and performing

The framework adopted for addressing this question draws on the new economic sociology (also termed cultural economy) that has been strongly influenced by socio-technical studies (STS; Amin and Thrift, 2004; du Gay and Pryke, 2002). It also meshes with the new valuation studies prompted by Stark's work (2009). This begins from the idea that greater attention needs to be paid to the construction of markets; markets are not natural phenomena but have to be actively created and maintained. New economic sociology, therefore, explicitly seeks to analyse the way that existing markets are constructed including the potential for other alternatives to emerge or exist (Law, 2002). From this perspective, markets can be seen as "complex entanglements or networks of humans, materials, institutions, politics and technologies" (Lovell and Smith, 2010: 458) which are rendered economic (Callon et al., 2007: 3). How "economic markets are separated out of the myriad connectivities in life and made into a recognisable working mechanism of exchange" is the focus of attention (Lovell and Smith, 2010: 459). As Hopwood states more simply: "a practical economy needs to be positively forged rather than merely revealed" (1992: 142).

Callon (2007) puts particular emphasis on the possibility of market transactions arising from the way that entities have been disentangled, decontextualised and alienated from specific relationships and given frames. A market object has to be created so it can be exchanged in market transactions as an abstract entity. The object to be traded needs to be reasonably stable and 'thing-like'; it cannot be too uncertain prior to the exchange or vary too much between individual exchanges. This also involves minimal agreement on the nature and limits of property rights and how they can change hands, and the existence of systems for surveillance and enforcement of exchanges. 
Considering the object of exchange in property markets, it is very tempting to see commercial property markets as a means of exchanging buildings and floorspace, i.e. the physical entity but what is actually exchanged is a property right, i.e. a set of rights and duties associated with the physical building or floorspace that are socially recognised and legally enforceable. From an STS perspective, the object of exchange is inherently sociomaterial, comprising a nexus of the set of rights and duties and a material part of the built environment, a physical building (or part of it) in a specific geographical location.

Furthermore, Callon emphasises that this process of object-construction is never complete so there is never a distinct, discrete, non-socially constructed market transaction. Rather there is continuous work involved in creating the possibility of the market exchange and there is always scope for change and disruption: "the game is never over, for new framings are always possible" (Callon, 2007: 321). This includes the possibility of sustainability frames. If a sustainable property is to become the object of exchange within the commercial property market, consideration needs to be given to how the object is constructed as sustainable and how the nature of the property right interfaces with the sustainability assessment of the materiality of the building.

A second feature that this approach draws attention to is the importance of modes of calculation, providing means for actors to calculate the probable outcomes of their choices. This includes, inter alia, the definition of standards and the existence of measuring systems. These aspects of markets all have to be built into institutional arrangements, routines, regulations and practices. Market devices are important means of achieving this; Callon, Millo and Muniesa see market devices as "material and discursive assemblages that intervene in the construction of markets" (2007: 2). Callon (1998a) argues for attention to 
the nature of calculation in these markets as a complex, collective practice with specific material realities in the form of artefacts such as figures, written media and inscriptions.

A specific form of calculation that is significant within markets is valuation; this is particularly important within property markets where there is a distinct professional activity of valuation. Callon and Caliskan $(2009,2010)$ emphasise the important of modalities of valuation within markets, examining these in practice whereas traditional economics takes these as given. This meshes with valuation studies (Stark, 2009; Berthoin Antal et al., 2015), developing a sociological analysis of how value is constructed and, further, the identity of valuers generated.

This perspective can help us understand what is involved when markets come under pressure for change, for example from the sustainability agenda; sustainability concerns introduce a previously unknown element into market calculations and valuations. Callon sees the solution to such uncertainty in the emergence of new calculative agencies and new calculating tools; for, as Callon emphasises “calculativeness didn't exist without calculating tools" (1998a: 23). From valuation studies, Hutter and Stark also emphasise that when something new emerges, someone has to determine its worth (2015: 1). Furthermore, to acquire value something has to be differentiated enough, recognisable enough and reproducible enough, but not too many elements should be involved in such differentiation. Thus a sustainability commercial property needs to be differentiated from other property and recognised as distinctly sustainable but without reference to too many characteristics. The incorporation of a value for a sustainable commercial property can be compared to the study of value-added accounting, which Mennicken and Power analyse as creating "a new kind of object in accounting terms and a mechanism for the production of an alternative 
reality, albeit within the existing frame of standardized corporate financial reporting" (2015: 210). Callon describes going beyond the established framings offered by existing calculative tools and practices as leading to 'overflowings' (1998b).

The emergence of new calculative tools potentially has significant impacts and thus the use of these tools may be considered performative, a concept that also much engaged Callon (1998a, p. 46). MacKenzie argues that Callon's version of performativity is very general, seeing social life as the results of 'endless performances' (2004: 305). He, therefore, favours a stronger version, which he terms Austinian, drawing on the idea of a performative utterance, where the speaking makes itself true; thus the person authorized to perform the marriage ceremony renders a couple married by declaring them so. There are a number of relevant examples of such performative analysis. Valuation studies has shown how the application of techniques of valuation can render preferences endogenous, as opposed to the techniques revealing a-priori established preference sets (Berthoin Antal et al., 2015); Hennebury and Roberts (2008) demonstrated how benchmarking for office property is a self-referential practice that has had prevented geographical diversification of investment; and Christophers (2014) has analysed how the role of the Three Dragons model for determining affordable housing levels in developments has made and remade the urban landscape.

If sustainability is to influence commercial property markets, this framework suggests that there will need to be a differentiated object of exchange that is the focus of calculative devices altering prevailing modalities of valuation and where tools play a performative role in altering practices. But the discussion of the partial financialisation of the commercial property market above suggests that such an analysis cannot be conducted for the market 
as a whole. The analysis below, therefore, presents two narratives, one for prime and one for non-prime property. In each case, the following are considered in relation to the sustainability agenda: constructing the object of exchange in the commercial property market; the modalities of valuation; and the role of a variety of calculative market devices, including their performative role.

\section{A note on methods}

The research for the paper employed a mix of methodological approaches. In additional to the usual research literature review, a web search was undertaken over 22-23/11/2013 for sites linked to the mix of terms "sustainable/sustainability", "property" and "commercial/offices/shops/retail". This gave access to the online professional and commercial literature. 29 sites were examined in depth and this was supplemented by a review of material in the Royal Institution of Chartered Surveyors (RICS) journal Modus and the BRE's (Building Research Establishment) weekly online news service Building4Change and a search for professionally and commercially-oriented books and reports in a copyright library.

A series of interviews with property market professionals were undertaken in 2014 . Two different sources were used for accessing potential interviewees. Using names revealed in these web-pages and professional press articles, together with contact lists from a number of relevant workshops during 2011-3, a database of commercial and professional actors was built. From these, 26 property market professionals were identified and current contact details were obtained for 15 , resulting in 9 interviews. As these interviewees were overwhelmingly professionals involved with prime commercial property and based in the centre of London, contacts involved in a broader range of property market transactions 
were sought. Estate agents identified in boards above empty or to let commercial properties in an area of north London were contacted. Together with some snowballing, this resulted in an additional 8 interviews. All interviewees were given a commitment of confidentiality to encourage them to speak openly. Digitally recording was considered inappropriate as it might deter the interviewee. It was therefore decided to record all the interviews manually, typing up detailed notes immediately after. Since these were not transcripts, analysis proceeded by reading and rereading rather than using a formal coding process. A summary note was prepared and circulated to all interviewees, inviting corrections and comments which were used to finalise the analysis. It should be noted that results were highly consistent within the prime and non-prime sectors.

Finally, research was undertaken through online material into the various calculative tools identified through literature searches and interviews. Interviewees were also specifically questioned about the significance of these tools. These insights were complemented by the author's previous knowledge of the emergence and operation of several of these tools through contacts with the organisations responsible for the tools.

\section{Sustainability and prime commercial property}

The analysis begins by considering how the object of exchange in the prime commercial property sector is constructed. A first important feature is how time is embedded in the object. Prime commercial property owners are assessing their assets on the basis that they will be holding properties for at least 10 years and potentially up to 25 years, letting them out on leases, which are currently averaging 10 years on a new lease with regular rent reviews (McNamara, 2015). This timescale puts a premium on ensuring the attractiveness of the property to tenants and its compliance with regulatory requirements over the medium 
term. Owners need to ensure that the property counts as 'prime' not just now, but for at least a decade ahead.

The interviews made it clear that this is resulting in actors in the market-place increasingly expecting green features in prime property and 'high' specifications meaning 'green' specifications. This is not a stable situation. With competition between buildings to be considered amongst the best, there is continuing pressure for improved specifications. The incorporation of more and more sustainability features is being expected at the 'top end' of the market and perceptions of quality are being amended accordingly. The interviews further revealed that, currently, the way the terms 'prime' and 'sustainable' are being used as markers of the highest quality in the property market is largely about energy, with double the mentions compared to accessibility and transportation, the next most common focus; this may relate to the greater energy intensity of prime property (Ellison \& Sayce, 2006, p.15).

Remembering that the object being exchanged is a legal right over a physical building, it is interesting to note that a new form of legal right, the green lease is featuring (Hinnels et al., 2008; Sayce et al., 2008). The distinctive characteristic of a green lease is that it requires the landlord and tenant to work together in the context of the physical features of the building to reduce energy consumption. This is intended to facilitate investments in energy efficiency measures as well as encouraging behavioural change by the tenants. Such green leases were introduced to overcome the split incentive problem that still pervades much of the UK property market, whereby the landlord incurs the costs of energy-related efficiency measures but the tenant reaps the reward in terms of lower utility bills; elsewhere in Europe landlords often pay energy bills. Even if a full green lease is not adopted, larger 
landlords are beginning to consider including lease terms to prevent tenants doing works that might be detrimental to the EPC rating; and some tenants are asking to be indemnified against liability for a non-compliant EPC rating post-2018.

Turning to the way in which prime and sustainable prime property is valued, the investment rationale of the major institutional investors means that the assumed risk and choice of discount rate are the key factors. The definition of 'prime' implies a low risk property investment, represented in the adoption of a low yield within the DCF. The low return from rental income as a percentage of capital value is accepted due to the expectation of lower variability in rental income and of rental and capital value growth. The fact that actual historic returns do not always reflect these assumptions (GVA, 2011) is not relevant; the calculative practices for valuation within the prime property sector still follow these conventions (Habib, 2013) and this means that the way risk is perceived and the capitalisation yield chosen is important.

Calculations in the prime property market are all about reducing risk, particularly risk of voids in the occupancy of a building which undermine the security of the income stream. Such voids may arise from the difficulty of getting a tenant or because there is a need to undertake refurbishments (say as a result of MEPS). Incorporating sustainability features has become a way of reducing risk and justifying a low yield in prime property valuations. The interviews suggested that the yields used to capitalise rental income are not being further adjusted for sustainability features. While a more sustainable building is considered less risky than a less sustainable building, the 'all risks' yield is assumed to have already factored in the risks associated with a best (and hence most sustainable) property. 
Risk is not just about attracting the best (most secure) tenants initially but about futureproofing with regard to regulatory requirements so as to avoid un-scheduled disruptions to occupancy. Prime property owners will look ahead and incorporate measures now to reduce the risks of any future loss of rental income and also consider them at planned major refurbishment points. In this way, prime buildings seek to be 'green' at inception and ordinary asset management maintains the sustainability of premises on an ongoing basis. For portfolios of prime properties, it was reported that the major institutional owners are reviewing their assets and calculating the works that would need to be undertaken to meet the requirements of MEPS. Using a DCF calculation, they are factoring in the necessary works over time and calculating the impact on the NPV of the asset. This is underpinning decisions about whether to keep, refurbish or sell the asset. Where they are deciding not to keep the building, it is redefined as non-prime due to obsolescence, valued with a higher discount rate (reducing its capital value) and released onto the secondary market.

Key classificatory tools play a role in such calculations. In the prime sector, EPCs and the implications of MEPS are incorporated into marketing, valuation and assessment of commercial property. There are some interesting cognitive disjunctures operating. While some interviewees questioned the robustness of the EPC methodology in relation to actual energy consumption, this does not affect the expectation of an A-grade. And while there is some scepticism about the likelihood of strict MEPS measures actually coming into force, expenditure in anticipation of MEPS is already being planned and institutions are also considering the simpler option of recalculating the EPC with better data as it is estimated that many older EPCs are likely to be 'inaccurate'. Outside of these major investors, there remains considerable inaction and a 'wait-and-see' attitude was widely reported. 
There are other ways in which this single classificatory framework of the EPC, backed by MEPS regulation, is likely to impact practices within the prime commercial property sector. These include: new modes of negotiation on rent reviews focussed around discounts for investments in energy efficiency by tenants; tenants countering dilapidations claims by landlords on the basis that necessary works for MEPS would replace the affected fixtures and fittings; generalised dispute over the locus of responsibility for energy improvements to make a building MEPS-compliant; and impacts on security of tenure if landlords need access to undertake improvement measures.

On new developments, the key classification schemes being incorporated into calculative practices are BREEAM and, to a less extent, SKA. An Excellent or Outstanding rating under BREEAM is looked for and expected on all new development in the prime sector. One interview referred to the BREEAM system as "great" - again regardless of how well it actually reflects sustainability - "because it is a badge". BREEAM is now incorporated into in-house systems for assessing properties and corporate reporting. The RICS-promoted SKA scheme plays a similar role with regard to fit-outs and refurbishments of existing commercial property.

Finally, there are now a number of classificatory schemes linking investment performance with sustainability assessment. Here the performance of individual or a groups of buildings is typically benchmarked against an investor's overall portfolio of buildings and a database for their peer comparators in the market. For example, GRE offer the GRE Sustainability Benchmark (GRESB) Report which includes a free scorecard and also a more detailed benchmark report available only to paid members. In marketing the tool, the benefits for ensuring due diligence are emphasised but also the potential for comparison against peer 
investors. This benchmark seems to be of growing importance in the investment market, as compared to its competitors EcoPAS (developed by IPD) or IPSI (from the Investment Property Forum with IPD involvement). It is regarded as research-based with a global reach, trading on the academic reputation of one of its founders, Nils Kok; it appears to be achieving the status that the IPD scheme and index have already found in the more general investment market (Hennebury and Robert, 2008). Investors are asking for a GRESB rating and even demanding performance in the top quartile of the GRESB global database. Funds which already contribute to GRESB require a rating for new acquisitions.

The classificatory tools of EPCS, BREEAM and GRESB provide is a de facto definition of sustainability in relation to individual buildings and whole portfolios, but they are also shaping investment decisions, on purchase and sale and on asset maintenance.

Performance is expected at certain levels and this will influence which buildings are bought and sold and whether they are retained in a portfolio. Sustainability - as represented by these specific classifications - is incorporated into the calculative practices of the prime commercial property market.

\section{Sustainability and non-prime commercial property}

The dynamics are different in the non-prime sector. To begin with, the object of exchange has a different timescale embedded in it. The key tenants are smaller firms and start-ups, which are generally operating on a 12 month horizon. This clearly affects the way that expenditure on sustainability features is viewed (Dixon, 2009). Thus, when asked to define sustainable commercial property in terms of three specific features, for two of the nonprime agents the term 'sustainability' had no meaning at all and all the rest focussed on the 
longevity of the business and the occupation of the premises rather than any 'green' building features.

This shorter time horizon is reflected in the object of exchange. Interviews suggested that standard new leases for small shops are 10 years with a 5 year rent review and tenants with a stronger covenant may be able to ask for a break clause at 5 years; Grade $\mathrm{C}$ offices are usually let on 6 years with 3 year rent reviews and start-ups will want even shorter leases at around 3 years. RICS data (2013) shows that the average length of new leases (which will be dominated by non-prime property) was less than 5 years in 2011 and that $76 \%$ of new leases are 1-5 years long. Average lease length in retail was 5.5 years, in offices 4.5 years and in industrials only 3.5 years. Most negotiations between tenants and landlords are not over the physical features of the building but on the possibility of a rent-free period, break clauses or a service charge cap. $33 \%$ of new leases have break clauses and the average rentfree period is 8.8 months (RICS, 2013). In more buoyant market conditions, tenants may have to pay a premium to get a tenancy. In the non-prime sector there is also a market in lease assignments, whereby the unexpired part of the lease is sold, often with the existing business. The 'goodwill' of the established business will form a part of the price of the remaining lease term alongside the capitalised value of any difference between the negotiated rent in the lease and the prevailing rental values (called the 'profit rent').

Thus the non-prime sector is characterised by a short timescale and a concern with occupancy by a rent-paying tenant in circumstances where business solvency cannot be taken for granted. At the 'bottom end' of the market are, as one agent put it, businesses that are concerned with whether they will be in business next week. Tenants are attracted by financial breaks not sustainability features. Where leases are sold, the object is 
constructed not just from the physical premises and the legal right but also the nature of business activity. This premises-business entanglement is also seen in the way that the nonprime commercial property sector is strongly impacted by policy measures affecting business viability, such as rates relief or incentives for SME start-ups.

The dynamics of calculation and valuation in the non-prime sector are also different. While the investment method continues to be used to calculate capital values, outside of the prime sector there is much greater use of comparables for capital values as well as rental levels and lease assignment values. For example, for small shop units, a standard rental level will be expected and sought by landlords which will then be adjusted for location and nearby competition for the specific business involved. Lease assignments have a similar benchmark price. The complexity of calculations is lower and DCF calculations are not typically undertaken.

This does not mean that risk does not feature in market calculations. Indeed the non-prime property owners is investing in this sector of the commercial property market because they want to get a higher return and are willing to accept a higher risk to get this. Non-prime property is inherently more risky for a range of reasons (GVA, 2011). It is often management intensive, capital intensive, potentially obsolete and more prone to voids and loss of income. The covenant strength of the tenants is weaker and when the market falls, properties are often over-rented and even short leases can make it a challenge to re-let buildings (GVA, 2011). The return is, therefore, higher than with prime property. Interviewees in North London reported that secondary property let on long leases to good covenants and subject to low rents per sq.ft. could be bought at yields of $6.5-7 \%$ which is 
nearly twice the yield on prime London property. Where the risk is considered higher, yields will reflect this, rising to $10 \%$ and even beyond.

So investing in sustainability features as a way of reducing risk has no attraction. Furthermore, non-prime investors typically hold a portfolio of many smaller properties and do not wish to engage in complicated programmes of works across the portfolio, particularly where there is unlikely be a value case for sustainability investments in terms of affecting rental or capital values. Tenants are often financially insecure and budget constrained and have little interest in sustainability (even energy bills) because they are more worried about paying rent, rates (the business property tax) and insurance costs; this is particularly the case for smaller shops. Furthermore, owners of non-prime property are concerned to ensure its liquidity and ease of sale or re-letting. This means offering a basic, substitutable product, usually an empty shell with minimal features that the tenant can fit out to their own needs.

Given this lack of incorporation of sustainability into the object of exchange in the nonprime sector, it is perhaps not surprising that classificatory forms of calculative tools attract much less interest. Interviews suggested that EPCs were considered a regulatory requirement in terms of box-ticking but it was universally claimed that occupiers, landlords and agents never looked at them or considered the recommendations for energy efficiency improvements that they contained. The existence of an EPC was sufficient for due diligence. In addition, non-prime property agents do not regard many of the properties that they deal with as likely to be affected by MEPS as they are already compliant or could readily be brought into compliance by new windows or frontages that a new tenant would probably require in any case. There is also considerable scepticism that MEPS will be fully enforced. 
The Trading Standards Office and local authority trading standards officers will be responsible but may well be insufficiently resourced to tackle this new task. Already many non-prime properties are advertised without mention of the EPC rating despite this being in contravention of regulations. The level of any penalties imposed will also be important and may be weighed up against the costs of required energy efficiency improvements.

For all these reasons, the percentage of the overall commercial stock that may be affected by MEPS is probably well below the $20 \%$ anticipated and disproportionately concentrated in larger secondary commercial premises that predate the improvements in the Building Regulations over the last decade or so. The Energy Act 2011 may have much less impact than hoped (by government) or feared (by the property sector). Given the nature of the calculative practices within the prime and non-prime property sectors, it cannot be assumed to deliver significant improvements in the energy efficiency of commercial buildings.

Beyond EPCs there was little cognisance of sustainability classificatory schemes. The one exception appears to be the RICS-backed SKA scheme for fit-outs, which is considered to have some potential in the secondary office market, where it could provide a low cost assessment of the quality of refurbishments and refits. But in general, the non-prime market is one in which sustainability is not integrated into valuation and calculative practices and there is, therefore, little perceived need for the tools offered by such classificatory schemes.

\section{Conclusions}

The analysis here proposes that the commercial property market can be viewed as partially financialised, with the prime sector adopting advanced finance techniques of valuation and creating new collective means of investment. This impacts on the engagement with the 
sustainability agenda for the commercial property sector. The longer time periods for investment characterising this sector means that sustainability, i.e. environmental sustainability has become a key marker of 'prime' in the construction of the object of exchange with sustainability classificatory tools playing important roles. Green specifications, A-Grade EPCs, Excellent or Outstanding BREEAM assessments and green leases (or the equivalent) all constitute the current meaning of sustainable/prime commercial property. Thus the object of exchange comprises a building with green specification, with landlord-tenant relations defined by commitments to energy reduction and subject to medium term asset management to maintain environmental sustainability performance. Yields are not being adjusted further for the low risk that such a property is seen to represent since they already represent the best investment that the prime sector can offer. The increasing traction of sustainability investment benchmarks also means that investors are looking for high sustainability performance in these terms and managing their portfolios accordingly.

In the non-prime sector, the object of exchange comprises a nexus of current and potential business activity and a standardised building unit with a low level of specification that allows for flexibility of use and greater market liquidity. This object is valued through comparables evidence with little recourse to calculative tools for measuring energy or sustainability performance; indeed the lack of attention to EPCs can border on non-compliance. Neither tenants nor owners see any financial advantage in sustainability investments and investors operating in this less-secure economic context actively seek a level of risk to enhance their financial returns. 
This has implications for the sustainability agenda for the built environment. Outside of the prime commercial property sector, there is little interest in or attention to future proofing commercial properties and this suggests that ensuring the sustainability agenda has purchase across the entire commercial property market may prove highly problematic; it is the financialised prime sector where sustainability is more likely to be achieved, at least in terms of environmental performance and reduced energy consumption. And yet the majority of commercial property are to be found in the non-prime sector suggesting the need for a new policy perspective.

The analysis has also demonstrated the value of the new economic sociology perspective, drawing attention to how the object of market exchanges is constructed and how modalities of valuation operate, including the use of specific calculative tools to assess aspects of environmental sustainability. Stark's point about the need to have calculative tools that provide a limited form of differentiation when markets change is also borne out. The object of sustainable property, at least within the prime sector, is differentiated by the use of a set of calculative tools which provide a relatively simplified form of assessment. Even if the calculation itself is relatively complex (as with the way that EPC grades and BREEAM scores are calculated and property investment benchmarking occurs) the market simplifies these by reference to the outcome - the EPC grade, the BREEAM outcome, the GRESBE assessment - and turns them into an abstraction. And these outcomes continue to have impact within the market, shaping investment, sale and upgrading decisions, even where the market actors do not consider them to be accurate in assessing sustainability performance. 
But the analysis also suggests that, in the commercial property sector at least, the object of exchange is not as disentangled and abstract as suggested at times by Callon (see also Slater, 2002). Commercial property market exchanges always involve a nexus of elements. In the prime sector, this nexus comprises the physical buildings, including its quality/green specifications, and the contractual relationship represented by the lease, which may be a green lease. In the non-prime sector, the nexus is better characterised in terms of a much simpler physical unit, the business activity carried out and the short-term, flexible contract of the landlord-tenant relationship. Here there is considerable negotiation over the terms of the lease, rent-free periods, etc. in order to obtain tenancies in less-stable economic circumstances. In the prime sector, the tenant is assumed to represent a good covenant, i.e. not be within an unstable economic sector; negotiations can then be over detailed specifications of the property. These difference, above all, represent a different approach to risk, with low risk being the rationale of the prime sector and the non-prime sectors accepting risk for higher returns.

Thus while the new economic sociology can provide a nuanced understanding of market interaction with the sustainability agenda, attention needs to be paid to the detailed constitution of the nexus involved in commercial property market exchanges and the associated scope for negotiation between market actors. The market object is not completely abstracted from the social relations of the market but rather constituted through such negotiative practices. 


\section{Acknowledgements}

Thanks to Rachel Weber for reading and commenting on a draft. Many thanks also to the very patient anonymous referees who were generous with their comments, suggestions and references and helped shape the paper considerably as it evolved.

\section{References}

Amin A and Thrift N Eds, 2004 The Blackwell Cultural Economy Reader (Blackwell, Oxford)

Ascui F and Lovell H, 2011, "As frames collide: making sense of carbon accounting" Accounting, Auditing and Accountability 24 978-999

Benford J and Burrows O, 2013, "Commercial property and financial stability" Bank of England Quarterly Bulletin Q1 48-58

Berthoin Antal A, Hutter M and Stark D, 2015, Moments of Valuation: exploring sites of dissonance (OUP, Oxford)

Calişkan K and Callon M, 2009, “Economization, Part 1: shifting attention from the economy towards processes of economization" Economy and Society 38 369-398

Calişkan K and Callon M, 2010, “Economization, Part 2: a research programme for the study of markets" Economy and Society 39 1-21

Callon M, 1998a, "Introduction" in The Laws of the Market Ed. M.Callon (Blackwell, Oxford) pp 1-57

Callon M, 1998b, “An essay on framing and overflowing: economic externalities revisited by sociology" in The Laws of the Market Ed. M Callon (Blackwell, Oxford) pp 244-269 
Callon M, 2007, "What does it mean to say that economics is performative?" in Do Economists Make Markets? Eds D MacKenzie, F Muniesa, and L Siu (Princeton UP, Princeton, NY) pp 311-357

Callon M, Millo Y and Muniesa F, 2007, "Introduction" in Market Devices Eds M Callon, Y Millo and F Muniesa (Blackwell, Oxford) p. 1-12

Chadha S, 2012, "Sustainability can help 'future-proof' commercial property market" Architects Journal 12 June

Chiapello E, 2015, "Financialisation of valuation" Human Studies 38 13-35

Christophers B, 2014, "Wild dragons in the city: urban political economy, affordable housing development and the performative world-making of economic models" International Journal of Urban and Regional Research 38 79-97

Christopherson S, Martin R and Pollard J, 2013, "Financialisation: roots and repercussions" Cambridge Journal of Regions, Economy and Society 6 351-357

Cole R, 2006, "Shared markets: coexisting building environmental assessment methods" Building Research and Information 34 357-371

Dixon T, 2009, “Barriers to Sustainable Commercial Property? What is holding back the growth of sustainable commercial buildings?" https://www.2degreesnetwork.com/groups/built-environment/resources/barrierssustainable-commercial-property/ du Gay P and Pryke M Eds, 2002, Cultural Economy: cultural analysis and commercial life (Sage, London) 
Ellison L and Sayce S, 2006, The Sustainability Property Appraisal Project Kingston University, London)

Fieldson R and Rai D, 2009, "An assessment of carbon emissions from retail fit-out in the United Kingdon" Journal of Retail and Leisure Property 8 243-258

Forreset R and Hirayama Y, 2015, "The financialisation of the social project: embedded liberalism, neoliberalism and home ownership" Urban Studies 52 233-244

Fuerst F and McAllister P, 2009, "An investigation of the effect of eco-labelling on office occupancy rates" JORSE 1 49-64

Fuerst F, van de Wetering J and Wyatt $P, 2013$, "Is intrinsic energy efficiency reflected in the pricing of office leases?" Building Research and Information 41 373-383

Government Office for Sciences, 2008, Powering Our Lives (BIS, London)

GVA, 2011, Putting Secondary Property First: exploring the challenges and opportunities of non-prime assets (GVA, London)

Habib B, 2013, “An unbalanced property market; a 'bubble' in London?” available at: https://www.ipd.com/research-updates/an-unbalanced-property-market-a-bubble-inlondon.html

Hennebury J and Roberts C, 2008, “Calculated inequality: portfolio benchmarking and regional office property investment in the UK" Urban Studies 45 1217-1245

Hinnells M, Bright S, Langley A, Woodford L, Shiellerup P and Bosteels T, 2008, "The greening of commercial leases" Journal of Property Investment and Finance 26 541-551 
HMG (2011) Carbon Plan, available at:

https://www.gov.uk/government/uploads/system/uploads/attachment data/file/47621/13

58-the-carbon-plan.pdf

Hopwood AG, 1992 "Accounting calculation and the shifting sphere of the economic" European Accounting Review 1 125-143

Hutter M and Stark D, 2015, "Pragmatist perspectives on valuation: an introduction" in Moments of Valuation Eds A Berthoin Antal, M Hutter and D Stark (OUP, Oxford) pp 1-12

Joss S, Cowley R, de Jong M, Müller B, Park BS, Rees W, Roseland M and Xxxx Y, 2015, Tomorrow's City Today: prospects for standardising sustainable urban development (University of Westminster, London)

Latour B, 2005, Reassembling the Social: An Introduction to Actor-Network-Theory (OUP, Oxford)

Law., J, 2002, "Economics as interference" in Cultural Economy: cultural analysis and commercial life Eds P du Gay and M Pryke (Sage, London) pp 21-38

Layfield D, 2013, “Turning carbon into gold: the financisalisation of international climate policy" Environmental Politics 22 901-917

Levy D and De Francesco A, 2008, The Impact of Sustainability on the Investment Environment: a case study of Australia (RICS Research Report, London)

Lovell H and Smith S, 2010, "Agencement in housing markets: the case of the UK construction industry" Geoforum 41 457-468 
Lützkendorf T and Lorenz D, 2005, “Sustainable property investment: valuing sustainable buildings through property performance assessment" Building Research and Information 33 $212-234$

MacKenzie D, 2004, "The big, bad wolf and the rational market: portfolio insurance, the 1987 crash and the performativity of economics" Economy and Society 33 303-334

MacKenzie D, Muniesa F and Siu L, 2007, "Introduction" in Do Economists Make Markets?

Eds D MacKenzie, F Muniesa and L Siu (Princeton UP, Princeton, NY) pp 1-19

Macnamara P (2015) "The changing nature of property investment: implications for urban planning" in Connections: Exploring Contemporary Planning Theory and Practice with Patsy Healey Eds J Hillier and J Metzger (Ashgate, London)

Meehan E, 1984,"Ratings and the institutional approach: a third answer to the commodity question" Critical Studies in Mass Communication 1216-225

Mennicken A and Power M, 2015, "Accounting and the plasticity of valuation" in Moments of Valuation Eds A Berthoin Antal, M Hutter and D Stark (OUP, Oxford) pp 208-228

Müller J, 2014, "An accounting revolution? The financialisation of standard setting" Critical Perspectives on Accounting 25 539-557

Newell G, 2009, "The significance of sustainability best practice in retail property" Journal of Retail and Leisure Property 8 259-271

RICS, 2009, Valuation Information Paper No. 13: Sustainability and commercial property (RICS, London)

RICS, 2013, Property Data Report 2013 (RICS, London) 
Sayce S, Ellison L and Parnell P, 2007, “Understanding investment drivers for UK sustainable property" Building Research and Information 35 629-643

Sayce S, Sundberg A, Parnell P and Cowling E, 2009, Journal of Retail and Leisure Property 8 273-284

Sayce S, Sundberg A and Clements B, 2010, "Is sustainability reflected in commercial property prices: an analysis of the evidence base" RICS Research Report (RICS, London)

Schweber L, 2013, "The effect of BREEAM on clients and construction professionals" Building Research and Information 41 129-145

Slater D, 2002, "From calculation to alienation: disentangling economic abstractions" Economy and Society $31234-249$

Stark D (with Beuna D, Grand M and Lukács J), 2009, The Sense of Dissonance: accounts of worth in economic life (Princeton University Press, Princeton NJ)

Thomas D, 2011, "Banks hold f250bn in non-prime debt" Financial Times June 8, available at: $\underline{\text { http://www.ft.com/cms/s/0/e41cf61c-91e1-11e0-b4a3- }}$

00144feab49a.html\#axzz3KkdTf7Ut

Warren-Myers G, 2012, "The value of sustainability in real estate: a review from a valuation perspective" Journal of Property Investment and Finance 30 115-144

Zhang Y and Andrew J, 2014, "Financialisation and the Conceptual Framework" Critical Perspectives on Accounting 25 17-26

Zurich, 2013, Energy and Sustainability Zurich White Paper (Zurich, London) 
Figure 1 Commercial Property Sector UK
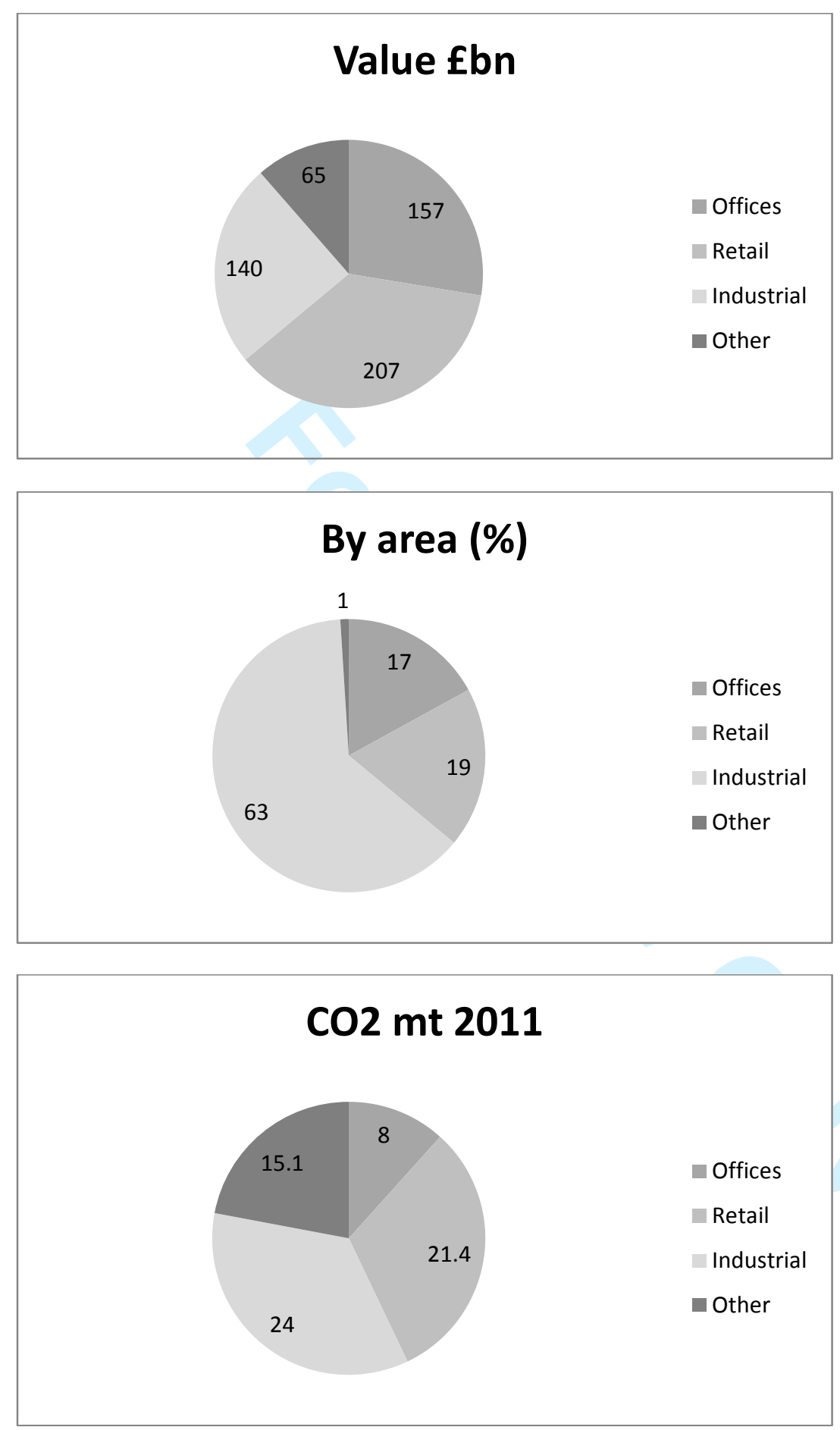

Source: GOS, 2008; RICS, 2013 